\title{
Polycentric or monocentric, which kind of spatial structure is better for promoting the green economy? Evidence from Chinese urban agglomerations
}

Yue Huang ( $\sim$ huangbeibeihenan@126.com )

Guangxi University of Finance and Economics

Ruiwen Liao

Guangxi University of Finance and Economics

\section{Research Article}

Keywords: green economy, urban agglomeration, spatial structure, monocentric, threshold effect

Posted Date: April 2nd, 2021

DOI: https://doi.org/10.21203/rs.3.rs-314418/v1

License: (c) (1) This work is licensed under a Creative Commons Attribution 4.0 International License.

Read Full License 

promoting the green economy? Evidence from Chinese urban agglomerations

Yue Huang ${ }^{1}$, Ruiwen Liao $^{2 *}$

1 School of Economics and Trade, Guangxi University of Finance and Economics, Nanning, China 2 Guangxi Institute of Finance and Economics, Guangxi University of Finance and Economics, Nanning,

\section{China}

Abstract: The green economy has gained worldwide attention, especially in the urban agglomerations where population and economic activities are highly concentrated. However, what kind of urban agglomeration spatial structure is more conducive to promoting the green economy? No clear conclusions have been made. Here, we study the impact of urban agglomeration spatial structure on the green economy, and also reveal how urban agglomeration spatial structure influences the three subsystems of green economy. We find that: (1) urban agglomeration spatial structural evolution is closely related to green economy, while in the research period, most urban agglomerations are not located in the optimal range of the spatial structure that drives the green economy. (2) Towards polycentric spatial structure is contributive to green economic growth, however, the excessively polycentric could not benefit green economy. (3) The evolution of urban agglomeration spatial structure exerts heterogenous impacts on the three subsystems when green economy is decomposed into economic subsystem, resources subsystem, and environmental subsystem. Towards polycentric is more conducive to the improvement of economic subsystem and resource subsystem, while, the tendency to monocentric drives the environmental subsystem development. (4) Lastly, our conclusions enlighten the urban agglomeration development planning and spatial mode for approaching a better performance in green economy.

Keywords: green economy; urban agglomeration; spatial structure; monocentric; threshold effect

\section{Introduction}

Urban agglomerations (The term urban agglomeration is closely linked to the term of urban cluster. It means the built-up zones of different cities are connected by continuous development. One prevailing

\footnotetext{
* Corresponding Author: Ruiwen Liao.

Email address: huangbeibeihenan@126.com (Y. Huang)

Ruiw_Liao@163.com (R. Liao)
} 
viewpoint is that, a typical urban agglomeration usually consists of at least 3 cities), accounting for over $75 \%$ of total domestic economic outputs, have become the most dynamic and promising areas for China's economic development now and in the future (Fang, 2015). However, the urban agglomerations also produce over $75 \%$ of the total pollution outputs, which consequently overload the ecological environment of the urban agglomerations (Fang et al., 2017). Compared with city individual, material and energy exchanges between urban agglomerations and other places (i.e., areas that do not belong to urban agglomerations) are more extensive and deeper, posing difficulties for urban agglomerations to solve increasingly severe resources and environmental constraints (Huang et al., 2021; Miao et al., 2021), and making green economy of urban agglomerations more complicated than ever before.

On the one hand, urban agglomerations are the most developed economic regions. On the other hand, urban agglomerations are also facing serious resource and environmental risks. Then, could we achieve a "multi-win" situation (i.e., economic growth, resources saving and environmental protection are obtained simultaneously)? In other words, could we achieve the green economy in the urban agglomerations? In fact, the Chinese government has been pursuing the construction of a resource-saving and environment-friendly society for many years, and has set up a "two-oriented society experimental zone" in the Chang-Zhu-Tan urban agglomeration (one of the urban agglomerations in China). Nevertheless, the problem of green development in China's urban agglomerations has not yet been fundamentally resolved. Presently, China is in the stage of accelerating the development of urbanization, and its city size distribution is also undergoing dynamic adjustment. Therefore, the following two issues emerge. How should the problem of green development of urban agglomerations be solved? Can the three aspects of economic growth, resource conservation and environmental protection be achieved through an appropriate urbanization development mode?

To address the aforementioned issues effectively, more and more scholars are focusing on urban spatial structure (e.g., the spatial distribution of population and employment) and are endeavoring to explore what kind of urban spatial structure can be beneficial to the urban development, i.e., exploring the growth effect caused by the urban spatial structure evolution. The two main research fields are as follows: first, a prevailing field about the economic growth effect, that is, the researches on whether and how urban spatial structure affect the economic efficiency and economic growth gap (Meijers and Burger, 2010; Garcia-López and Muñiz, 2013; Liu et al., 2017a; Zhang et al., 2017; Li et al., 2018; Li et al., 2019; Nijman and Wei, 2020). Second, a research field concerning the resources and environmental 
effect caused by the evolution of urban spatial structure, that is, how does the urban spatial structure affect the resources utilization and pollution emissions (Clark et al., 2011; Burgalassi and Luzzati, 2015; Hankey and Marshall, 2017; Muñiz and Sánchez, 2018; Muñiz and Garcia-López, 2019; Han et al., 2020; Lee and Lee, 2020; Liu et al., 2020).

After a review of the existing papers, we find that, when they analyze the growth effects of urban spatial structure (e.g., the relationship between urban spatial structure and economic performance, urban spatial structure and growth efficiency, urban spatial structure and environmental governance, etc.), most of the papers focus on the growth effect in a single perspective, e.g., "how does the evolution of urban spatial structure affect the economy" and "how does the evolution of urban spatial structure affect the environment" are researched separately. Although a single research objective is necessary for a deeper cognition in its own field, an integrated objective is still needed, because ignoring or weakening any aspects is not conducive to the green economy.

Admittedly, the existing findings enlighten this article theoretically and empirically. However, as of now, the integrated effects caused by the spatial structural evolution has not attracted sufficient attention. The topic about what impact the rapid spatial structure evolution of urban agglomerations have on the development of green economy are still not effectively revealed or addressed. Although a bit of literature has paid attention to similar topic (Liu et al., 2020; Miao et al., 2021), the evidence is still few. It is obvious that bridging this gap is necessary for China, in which many urban agglomerations are being constructed and green development is urgently required. It helps to reveal the relationship between the spatial structural evolution of urban agglomerations and the green economy.

Particularly, in recent years, polycentric spatial structure (one of the evolutionary stages of urban spatial structure) has drawn scholars' attention. After the Copenhagen Climate Conference in 2009, more and more attention has been paid to environmental problems, and the polycentric has been regarded as an efficient urban form to promote sustainable development (Vandermotten et al., 2008) than ever before. However, whether spatial structure, especially polycentric, can truly improve regional competitiveness, promote regional balanced development and environmentally sustainable development, still lack empirical evidence.

This is a research topic worth discussing, because different cities may adopt completely inconsistent or differentiated strategies when facing the economic and environmental problems. For example, due to the existence of "promotion tournaments" (e.g., pursuing political promotion for one 
governor by means of achieving better economic performance than other governors, in other words, the better the economic performance one governor has, the higher possibility of promotion in political areas he/she has), neighboring cities may adopt mutually competitive strategies to develop the economy (Zhou, 2007). Thus, urban agglomeration may have a positive effect on the economy, and the economic growth of individual cities in turn affects the development of urban agglomeration. This forms a positive interaction between the spatial structural evolution of urban agglomeration and economic growth. However, the competition pattern (promotion tournaments) does not seem to be suitable for the environmental aspect, especially environmental policy. The extant literature has pointed out that there are "externalities" in environmental pollution and environmental governance, and the externalities may trigger the "free-riding" behavior in environmental governance (Sigman, 2005; Konisky and Woods, 2010). Therefore, the development of urban agglomerations and the evolution of their spatial structure may have different effects on the three dimensions of economy, resources, and environment. Such guess requires an effective empirical evidence, through which how urban agglomeration spatial structure affects green economy can be clearly shown.

The main contribution of our paper is threefold. First, we try our best to explore the impact of urban agglomeration spatial structure on green economy, such research until now only has received a bit of evidence from the existing papers. By doing this, we probably can reveal which spatial structure better is, polycentric or monocentric? This is essential in determining better strategies that are for future planning in terms of urban agglomerations. Second, we divide the green economy into three subsystems and show how the urban agglomeration spatial structure affects them. This helps to have a clearer picture of whether urban agglomeration can achieve economic growth, resource conservation and environmental protection together. It is also a supplement to existing research about the growth effect of urban spatial structure. Third, we make another contribution to the existing papers by simultaneously using the linear model and panel threshold model in an empirical framework, through which some new findings are found compared with the traditional empirical cases. Previous studies usually asserted spatial structure influence on economic growth or pollution emissions from linear perspective. However, the linear perspective might not be the best case for exploring the growth effects stem from the spatial structure of urban agglomerations. Actually, a threshold may be triggered and occur when the spatial structural evolution goes on. Using a panel threshold model allows us to obtain more clear insights in the growth effect caused by spatial structural evolution of urban agglomerations. 
To fulfill the above contribution in this study, we investigate the following research questions: Is

there evidence of spatial structure's influence on green economy in the urban agglomerations over the sample period? If so, further, we want to know when the green economy is subdivided into three different subsystems, whether the impacts on three subsystems show heterogeneities? Moreover, after the threshold model is conducted, what new findings can we get? Could the empirical findings confirm the superiority of the threshold model compared to the linear model?

The rest of this paper is organized as follows. Section 2 describes the study areas, key variables, and empirical methodologies. Section 3 explores the empirical results. Finally, concluding remarks are shown in Section 4. The specific research framework of this paper is shown in a graphical way (Fig. 1).

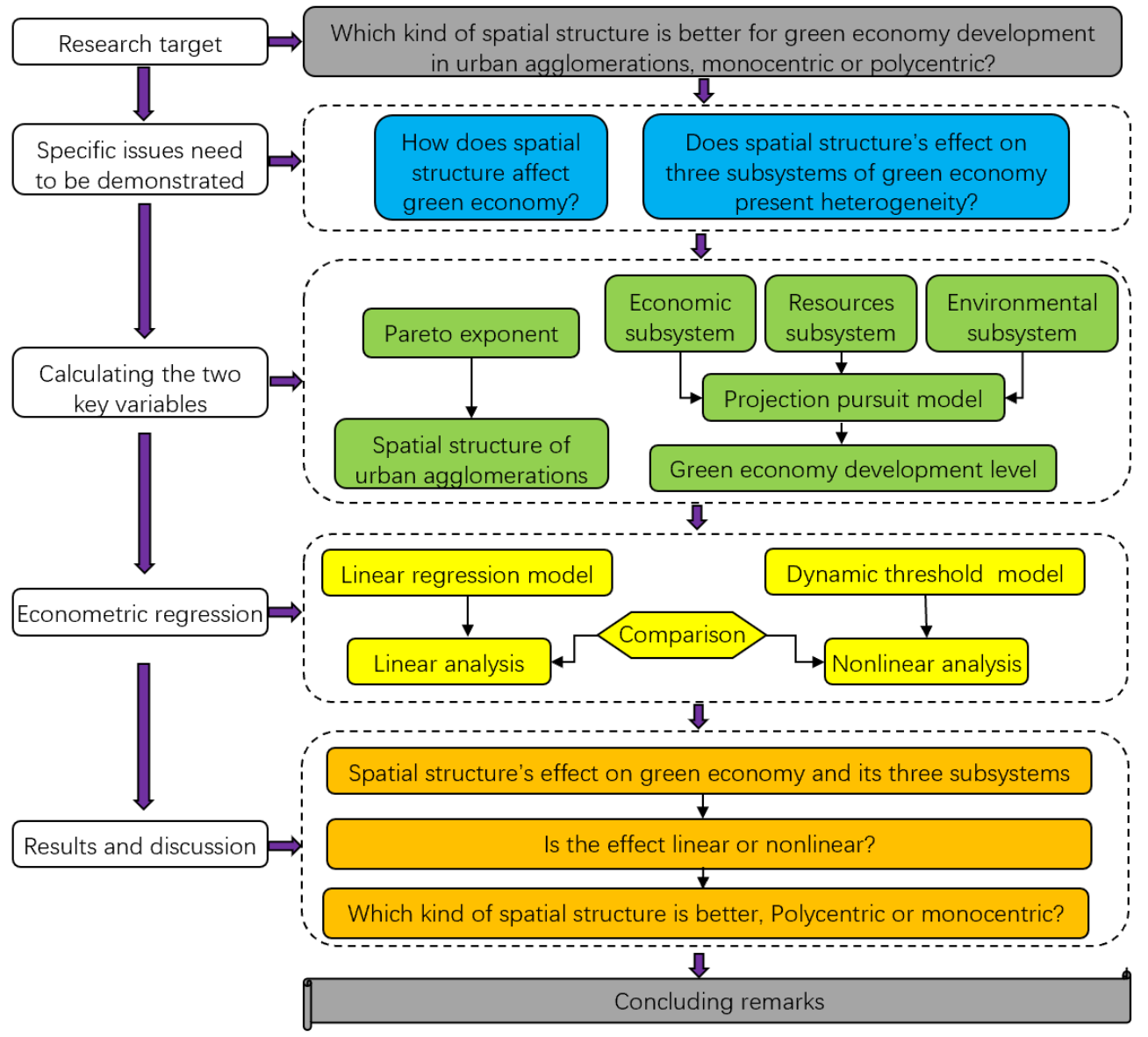

Fig. 1. Research framework

\section{Study areas, key variables and econometric strategies}

\subsection{Study areas}

Since the implementation of economic reform and urban agglomerations development planning, the urban agglomerations in China have experienced rapid economic growth and rapid urbanization, 
resulting in a continuous change in the city size and ranking, the extensive resources utility, the high-speed increase in energy consumptions and pollution emissions. China now is trying its best to make a high-quality development, therefore, to provide scientific support for the urban agglomerations is imperative. In existing references, number for the urban agglomerations in China varies across scenarios, for instance, 20 urban agglomerations asserted in existing papers (Fang, 2015; Fang et al., 2017) and 19 urban agglomerations mentioned in the 13th Five-Year plan of Chinese government. We follow the former one to proceed our research, the 20 urban agglomerations are mapped in Fig.2. It should be noted that, in this paper, we exclude four urban agglomerations, i.e., Northern Tianshan Mountain, Ningxia Yellow River, Lan-Xi and Qianzhong that are labelled in Fig. 2, because of limited statistical period for data. Thus, we obtain the remaining 16 urban agglomerations as the study areas.

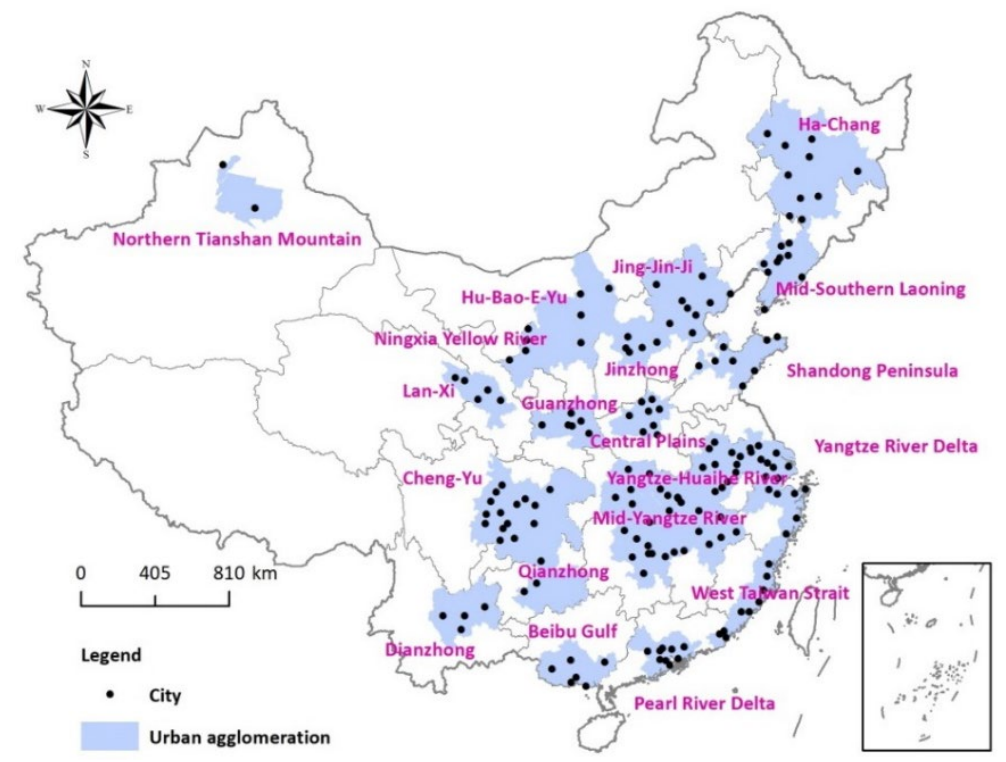

Fig. 2. The main urban agglomerations in China

\subsection{Two key variables and corresponding data processing}

\subsubsection{Key variable 1: spatial structure of urban agglomerations}

Evaluating the spatial structure of urban agglomerations is the basic work. Methods for assessing spatial structure (i.e., monocentric/polycentric) differs in previous papers. Following the paper (Meijers, 2008), we employ one of the prevailing indices, i.e., Pareto exponent, to calculate the spatial structure of urban agglomerations, which measures how quickly size declines when ordering cities from largest to smallest (i.e., measuring the overall degree of disparity in the size distribution), and show it as below:

$$
\ln (\text { Citysize })=\alpha-\beta \ln (\text { Rank })
$$


where Rank represents the urban population rank of each city that belongs to each urban 153 agglomeration. Citysize is the total urban population of each city. Coefficient $\beta$ is the monocentric

index: $\beta>1$ represents the monocentric spatial structure; $\beta<1$ means the polycentric one; $\beta=1$ denotes that the spatial structure is in line with Pareto distribution.

Admittedly, the Pareto exponent have some flaws for different fitting degree $\left(R^{2}\right)$ in different prefecture regions and may not comparable for a disparate number of sub-cities (Meijers and Burger, 2010; Li et al., 2018). Therefore, in this paper, the method of previous papers (Meijers and Burger, 2010; Liu et al., 2017b) is used to calculate the monocentric index $\beta$, that is, according to equation (1), the top two, top three and top four cities in each urban agglomeration are regressed respectively (i.e., calculate the slope of the regression line of city rank-size distribution in each urban agglomeration) and then the three values are averaged to get the monocentric index $\beta$.

Fig. 3 highlights the differences and changes of the monocentric index of 16 urban agglomerations according to the equation (1), and the value 1 means the Pareto distribution line. Main findings are as follows: (1) Overall, average scores for urban agglomeration monocentric index decreases from 1.1067 in 2003 to 1.0409 in 2017. (2) Monocentric urban agglomerations account for nearly a half (right hand in the figure); some urban agglomerations experience a decreasing monocentric score, i.e., towards the polycentricity, (e.g., Yangtze River Delta urban agglomeration); while some other urban agglomerations that were initially polycentric became monocentric (e.g., Beibu-Gulf urban agglomeration).

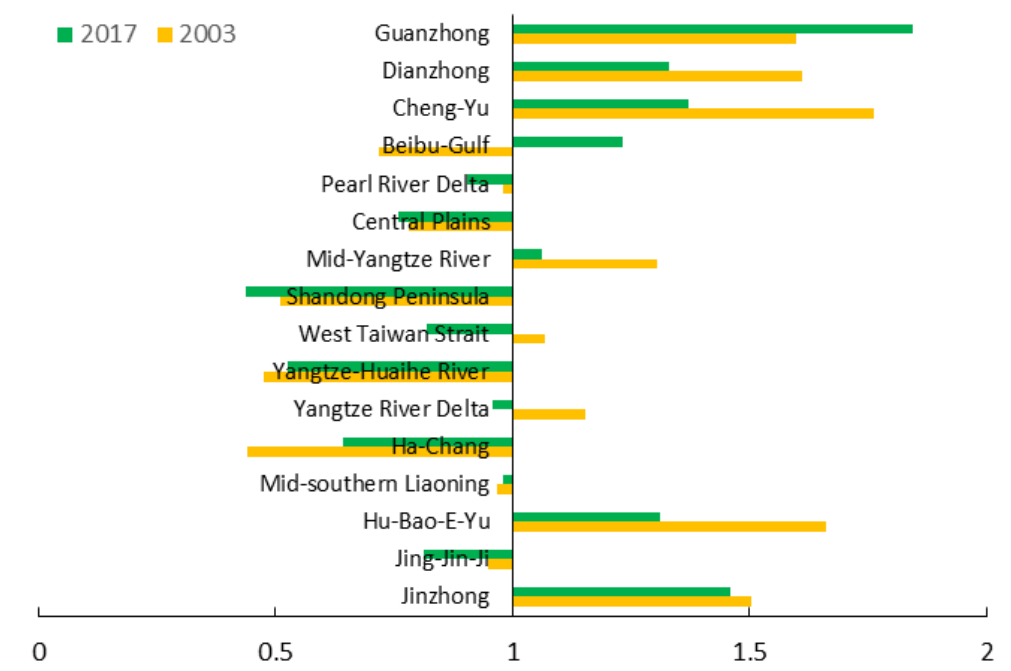

Fig. 3. Monocentric index value for 16 urban agglomerations in 2003 and 2017 


\subsubsection{Key variable 2: Green economy development level of urban agglomerations}

Now, we set a comprehensive evaluation indicator system to calculate the green economy development level of the 16 urban agglomerations. Since the green economy first proposed by Pearce et al. in 1989, its connotation has gradually enriched, and papers related to the evaluation approaches, assessing tools and research perspectives of green economy are substantial. For example, if scholars want to evaluate the development of green economy, they can choose methodology such as comprehensive evaluation (Huang and Li, 2017; Wang et al., 2019; Wu et al., 2021; Abid et al., 2021), efficiency measurement (Ringel et al., 2016; Miao et al., 2019; Pan et al., 2019; Wang et al., 2019), cost-benefit analysis (Söderqvist et al., 2015; Zhang et al., 2017; Carroll and Couzo, 2021; Owsianiak, et al., 2021; Li et al., 2021), and life cycle assessment (Finnveden et al., 2009; Hoogmartens et al., 2014; Röck et al., 2020; Gupta et al., 2020). In a paper, titled Green economy and related concepts: An overview, published by Loiseau et al. (2016), the authors concluded that over half of the keywords related to "green economy" belong to the semantic fields of economy, environment, resources (e.g., issues named economic development, growth, cost, climate change, renewable resources, energy consumption). Actually, it is difficult to get a comprehensive and systematic indicator system to measure the development of green economy because of abundant connotations of green economy itself (Gregorio et al., 2018). In our paper, we follow the conclusion made by Loiseau et al. (2016), and also refer to the findings recently made by D'Amato et al. (2017, 2019a, 2019b) to deal with the connotation of green economy. That is, the following three subsystems economy, resource, and environment are used to evaluate the green economy of Chinese urban agglomerations.

Selecting indicators used for evaluating the green economy is the primary procedure. However, due to the lack of statistical data, constructing a database for cities is always not easy. Based on the existing papers (Xie et al., 2016; Haider et al., 2018; Tian and Sun, 2018; Merino-Saum et al., 2018; Verma and Raghubanshi, 2018; Zhang et al., 2018; Wang et al., 2019; Wu et al., 2021), we construct evaluation indicator system (Table 1) containing three levels: the first one is the target level, which represents green economy; the second one is standard level, including the three subsystems economy, resources and environment; the third one is the indicator level, containing a total of 19 indicators.

Table 1. Comprehensive evaluation indicator system for green economy

\begin{tabular}{|c|c|c|c|}
\hline Target & Standard & Indicator & Indicator \\
\hline
\end{tabular}




\begin{tabular}{|c|c|c|c|}
\hline level & level & level & attribute \\
\hline & & Per capita GDP & + \\
\hline & & Fiscal revenue & + \\
\hline & & Total fixed assets investment & + \\
\hline & Economic subsystem & & \\
\hline & & Proportion of tertiary industry to GDP & + \\
\hline & & Secondary industry labor productivity & + \\
\hline & & Tertiary industry labor productivity & + \\
\hline & & Public green area per capita & + \\
\hline & & Green coverage rate of built-up areas & + \\
\hline & & Water possession per capita & + \\
\hline & Resources subsystem & & \\
\hline \multirow[t]{10}{*}{ Green economy } & & Electricity consumption per GDP & - \\
\hline & & Water usage per GDP & - \\
\hline & & Growing rate of built-up land & + \\
\hline & & Urban wastewater treatment rate & + \\
\hline & & Hazard-free treatment rate of household garbage & + \\
\hline & & Comprehensive utilization rate of industrial solid waste & + \\
\hline & Environmental subsystem & Industrial sulfur dioxide emissions & - \\
\hline & & Industrial dust emissions & - \\
\hline & & Industrial waste water discharges & - \\
\hline & & Carbon dioxide emissions & - \\
\hline
\end{tabular}

Notes: we divide the selected indicators into "+" (rising) and "-" (constrained) based on their attributes. Among them, the " + " means an indicator that positively drives the green economy, a higher value usually means a stronger ability for green economy; and the "-" indicates the environmental and resources cost paid for the economic growth, i.e., a lower value implies a better performance of green economy.

Next, we proceed with the method for calculating the indicator system. In the extant literature, several comprehensive evaluation methods are commonly used. Such as principal component analysis method, factor analysis method, entropy weight method and TOPSIS method. In this paper, we use the projection pursuit model (PPM) to evaluate the green economy development level based on the indicator system (Espezua, et al., 2014). The PPM can avoid the loss of useful indicator information, 
resulting in a relatively full reflection of things that are evaluated (Wei et al., 2016). Especially, when managing data characterized by high-dimensional nonlinear and non-normal, the PPM is a highly accurate statistical method (Wei et al., 2016). Steps for modeling are shown below.

First, we standardize the indicators contained in the evaluation system (Table 1).

$$
x_{i}^{\prime}=\left\{\begin{array}{l}
\left(x_{i}-\min x_{i}\right) /\left(\max x_{i}-\min x_{i}\right), x_{i} \text { is rising indicator } \\
\left(\max x_{i}-x_{i}\right) /\left(\max x_{i}-\min x_{i}\right), x_{i} \text { is constrained indicator }
\end{array}\right.
$$

Second, we construct a projection indicator function. Suppose that $a=\left\{a_{1}, a_{2}, \cdots, a_{n}\right\}$ is n-dimensional unit vector, and $Z_{i}$ denotes the projected characteristic value of $Z_{i j}$, i.e., $i=1,2, \cdots m$, $j=1,2, \cdots n$, which can be depicted as follows:

$$
Z_{i}=\sum_{j=1}^{n} a_{j} x_{i j}
$$

Next, we construct the projected objective function of green economy, which contains more information compared with $Z_{i}$ :

$$
Q(a)=S(a) \times D(a)
$$

where $S(a)$ is the standard deviation of $Z_{i}$, and $D(a)$ is the local density of $Z_{i}$, formulas are as follows:

$$
\begin{gathered}
S(a)=\sqrt{\sum_{i}^{m}\left(Z_{i}-E\right)^{2} /(m-1)} \\
D(a)=\sum_{i=1}^{m} \sum_{j=1}^{n}\left(R-r_{i j}\right) \times u\left(R-r_{i j}\right)
\end{gathered}
$$

where $\mathrm{E}$ is the mean value of $Z_{i} ; R$ is the window radium of the local density usually taken as 0.01 ; $r_{i j}=\left|Z_{i}-Z_{j}\right|$ is the distance between a certain-two projected characteristic values; $u(t)$ is unit step function (indicator function), and $u(t)=\left\{\begin{array}{l}1, t \geq 0 \\ 0, t<0\end{array}\right.$. Finally, according to the constraints:

$$
\left\{\begin{array}{l}
\max Q(a)=S(a) D(a) \\
\sum_{1}^{n} a^{2}(j)=1
\end{array}\right.
$$
The optimal projection direction $a_{j}$ will be calculated, which refers to the weight of each indicator. 
agglomerations can be obtained by putting $a_{j}$ into formula (3). We can also calculate scores of the three subsystems economy, resource and environment based on formula (3).

Fig. 4 presents the score of green economy and its three subsystems in 16 urban agglomerations from 2003 to 2017 calculated by the PPM. As can be seen, first, the average value of green economy rises from 0.4269 in 2003 to 1.0733 in 2017, indicating an improvement in green economy. Second, the values of three subsystems of green economy differ a lot. The economic subsystem and resources subsystem witness a continuous rise, and the environmental subsystem shows only slight increasement, the rankings of resources subsystem exceeds the environmental subsystem in the second half.

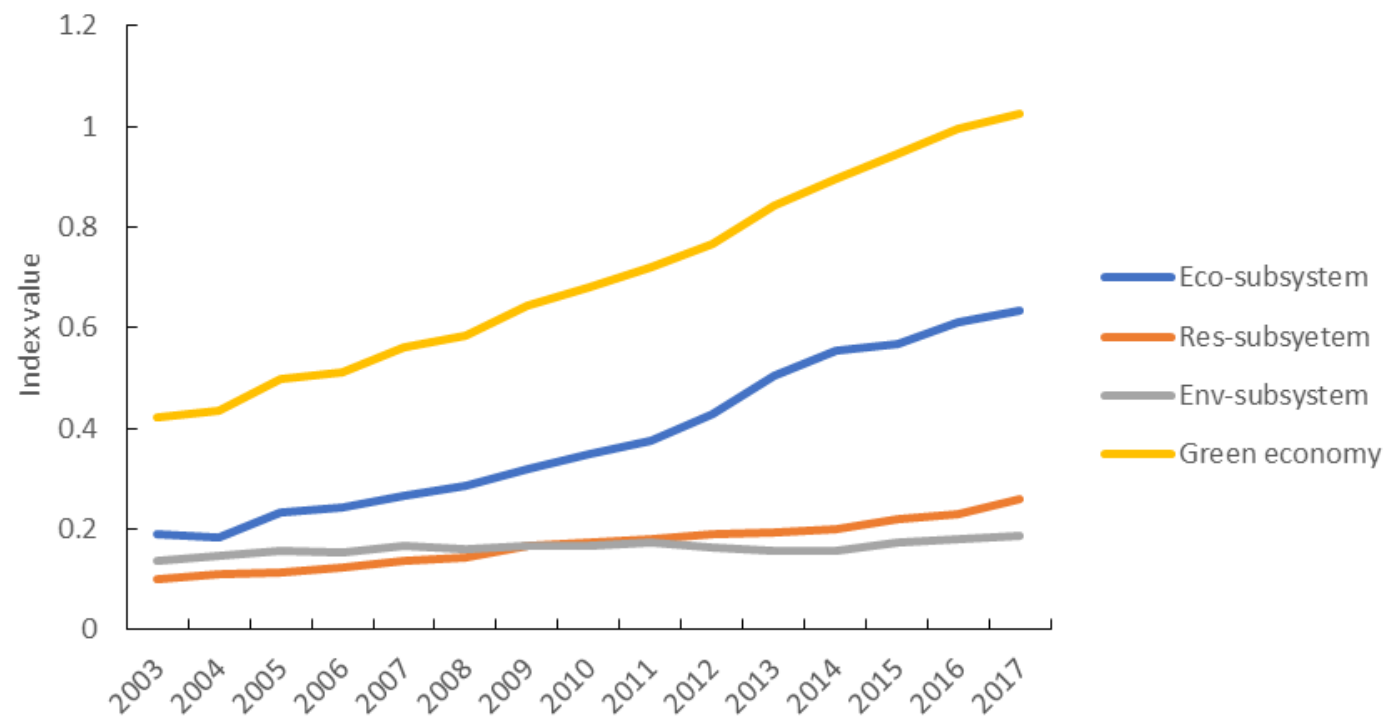

Fig. 4. Average scores for green economy and three subsystems across years in 16 urban agglomerations

\subsection{Econometric strategies}

\subsubsection{Baseline linear model}

To empirically check the effect of urban agglomeration spatial structure on green economy, we start our econometric models with a baseline panel regression model shown below.

$$
G E_{i t}=\beta_{0}+\beta_{1} \text { Mono }_{i t}+\beta_{j} \sum \text { Control }_{j i t}+\theta_{i}+\delta_{t}+\varepsilon_{i t}
$$

where $G E_{i t}$ means the green economy, $M o n o_{i t}$ represents the monocentric index, subscripts $i$ and $t$ denote urban agglomeration and time, respectively. Control $_{j i t}$ is the control variables, including 
the foreign direct investment (FDI), research and development investment (R\&D) and urbanization rate (Urban), all of which are closely related to the green economy development level, because of their influences on the economic growth, resources utility and pollution emissions (Glaeser and Kahn, 2010; Huang et al., 2018; Lau et al., 2014; Omri et al., 2014; Zhang et al., 2017). $\quad \beta_{j}$ represents the coefficients of control variables. $\beta_{1}$ is coefficient to be checked, $\beta_{0}$ is the constant. $\theta_{i}$ is individual effect, $\delta_{t}$ is time effect, and $\varepsilon_{i t}$ is random error.

As mentioned in previous papers (Meijers and Burger, 2010), there are probably endogeneity problems when analyzing the impact of spatial structure on economic productivity, therefore, we set up another two models to address the endogeneity problems in empirical test. We employ an empirical model with a time lag for the all the explanatory variables based on equation (8), and show it as below.

$$
G E_{i t}=\beta_{0}+\beta_{1} \text { Mono }_{i t-1}+\beta_{j} \sum \text { Control }_{j i t-1}+\theta_{i}+\delta_{t}+\varepsilon_{i t}
$$

Further, as is known, a dynamic panel model improved by previous papers (Arellano and Bond, 1991; Blundell and Bond, 1998) is another effective and convincing way to alleviate the endogeneity problems in regression analysis. Therefore, based on equation (8), a dynamic panel model, in which one period lagged of the green economy development level $\left(G E_{i t-1}\right)$ is captured, is set to check the effects of spatial structure on green economy, corresponding model is shown below.

$$
G E_{i t}=\beta_{0}+G E_{i, t-1}+\beta_{1} \text { Mono }_{i t}+\beta_{j} \sum_{\text {Control }_{j i t}}+\theta_{i}+\delta_{t}+\varepsilon_{i t}
$$

\subsubsection{Dynamic panel threshold model}

The effects of urban agglomeration spatial structure on green economy may vary across the monocentric index (the proxy of spatial structure used in this paper), and show different characteristics. In other words, different monocentric index range may bring various green economic growth effects, and there is probably a nonlinear relationship between spatial structure and green economy. To verify such hypothesis, a panel threshold model originally proposed by Hansen (1999) and Hansen (2000) could be used. First, we have the threshold model with one threshold value described as follows:

$$
G E_{i t}=\beta_{0}+\beta_{1} \text { Mono }_{i t} \cdot 1\left(\text { Mono }_{i t} \leq \gamma\right)+\beta_{2} \text { Mono }_{i t} \cdot 1\left(\text { Mono }_{i t}>\gamma\right)+\beta_{j} \sum \text { Control }_{j i t}+\varepsilon_{i t}
$$

where $1(\cdot)$ represents the indicator function. When the expression in parentheses is false, the value is 
0 ; otherwise, the value is $1 . M$ non $_{i t}$ is the threshold variable, $\gamma$ is the threshold value, $\beta_{1}$ is the threshold coefficient when Mono $_{i t}$ is lower than $\gamma$, and $\beta_{2}$ is the threshold coefficient when Mono $_{i t}$ is higher than $\gamma$. Control variables are same as those in equation (8). $\beta_{j}$ represents the coefficients of control variables.

It should be noted that there may be endogeneity problems in empirical test as we assert in previous context of this paper. Thus, the empirical tests based on equation (11), the static threshold model, maybe biased. To solve this, we apply the dynamic panel threshold model developed by the existing papers (Kremer et al., 2013; Seo and Shin; 2016) that extend Hansen's (1999) static model for endogenous regressors. The dynamic model with single threshold is below:

$$
G E_{i t}=\beta_{0}+\beta_{1} G E_{i t-1}+\beta_{2} \text { Mono }_{i t} \cdot 1\left(\text { Mono }_{i t} \leq \gamma\right)+\beta_{3} \text { Mono }_{i t} \cdot 1\left(\text { Mono }_{i t}>\gamma\right)+\beta_{j} \sum \text { Control }_{j i t}+\varepsilon_{i t}
$$

where $G E_{i t-1}$ denotes the one period lagged of the green economy development level, $\gamma$ means the threshold value, and the generalized method of moments (GMM) estimation is used in order to allow for the endogeneity.

Further, if the single threshold holds, we should test whether the multi-threshold could be observed, Then, the dynamic threshold model with a multi-threshold, such as double threshold model, can be shown below:

$$
\begin{aligned}
& G E_{i t}=\beta_{0}+\beta_{1} G E_{i t-1}+\beta_{2} \text { Mono }_{i t} \cdot 1\left(\text { Mono }_{i t} \leq \gamma_{1}\right)+\beta_{3} \text { Mono }_{i t} \cdot 1\left(\gamma_{1}<\text { Mono }_{i t} \leq \gamma_{2}\right)+ \\
& \beta_{4} \text { Mono }_{i t} \cdot 1\left(\text { Mono }_{i t}>\gamma_{2}\right)+\beta_{j} \sum \text { Control }_{j i t}+\varepsilon_{i t}
\end{aligned}
$$

\subsection{Data sources}

Data used for assessing the green economy development level and spatial structure of urban agglomerations are collected from official sources including China City Statistical Yearbook (CCSY, 2004-2018), and the EPS database (EPS-CHINA DATA, http://www.epsnet.com.cn/) is used for crosscheck. Data of control variables employed in the empirical tests are also obtained from the EPS database. Particularly, owing to the lack in official statistics, the carbon dioxide emissions labeled in the indicator system is an estimated data, based on the method presented in previous papers ( $\mathrm{Li}$ and $\mathrm{Wu}$, 2017; Wang et al., 2019). Some missing data are supplemented by averaging method.

\section{Econometric results}


This section presents the empirical findings of the baseline linear mode and dynamic threshold model to examine the influence of urban agglomeration spatial structure on green economy.

\subsection{Empirical results 1: how does spatial structure affect the green economy}

\subsubsection{Baseline linear model results}

Table 2 presents the regression results. Column (1) shows the coefficients based on equation (8), in which both individual effect and time effect are controlled, it is evident that the monocentric index and green economy is negatively correlated, and shows statistical significance at the $5 \%$ level. A $1 \%$ increase in monocentric index induces a $0.3371 \%$ decrease in green economy, that is, towards the monocentric spatial structure constrains the improvement of green economy. Since the decrease in monocentric index means a polycentric trend; therefore, we assert that the evolution to polycentric of urban agglomeration spatial structure in China contributes to the green economy than that in monocentric one.

To ensure a robust result, we make another three regressions, all of which also could alleviate the endogeneity to some degree. The first two regressions are: a one-order-lagged and two-order-lagged of explanatory variables based on the linear model (equation 9), respectively, and the results are shown in columns (2) and (3); the third regression is checked based on dynamic model (equation 10) with the prevailing SYS-GMM estimation; it is clearly that all the coefficients present expected results except minor fluctuations in significance and magnitude. Additionally, the three control variables are all significantly and robustly related to green economy, indicating their influence on green economy.

Table 2. Linear regression results: test for green economy

(1)

\begin{tabular}{|c|c|c|c|c|}
\hline & No lag in Mono & One-order lag in Mono & Two-order lag in Mono & SYS-GMM \\
\hline \multirow[t]{2}{*}{ GE (-1) } & & & & $0.6791^{* * *+}$ \\
\hline & & & & (3.74) \\
\hline \multirow[t]{2}{*}{ Mono } & $-0.3371^{* *}$ & & & $-0.5582^{* * *}$ \\
\hline & $(-2.05)$ & & & $(-2.44)$ \\
\hline \multirow[t]{2}{*}{ Mono (-1) } & & $-0.4093^{* * *+}$ & & \\
\hline & & $(-3.57)$ & & \\
\hline
\end{tabular}

(3) (4) 


\begin{tabular}{|c|c|c|c|c|}
\hline \multirow[t]{2}{*}{ Mono (-2) } & & \multicolumn{3}{|c|}{$-0.3222^{*}$} \\
\hline & & & $(-1.91)$ & \\
\hline \multirow[t]{2}{*}{ FDI } & $-0.2732^{* * *}$ & $-0.2411^{* *}$ & $-0.1715^{*}$ & $-0.3321^{* *}$ \\
\hline & $(-3.74)$ & $(-2.07)$ & $(-1.87)$ & $(-2.12)$ \\
\hline \multirow[t]{2}{*}{ Urbanization } & $0.1011^{* * *}$ & $0.1226^{* * *}$ & $0.0820^{* * *}$ & $0.1242^{* * *}$ \\
\hline & $(2.77)$ & $(4.98)$ & (3.94) & (5.39) \\
\hline \multirow[t]{2}{*}{ R\&D } & $0.9141^{*}$ & $1.1793^{* * *}$ & $1.0091^{*}$ & $1.0847^{* * *}$ \\
\hline & (1.91) & (3.38) & $(1.77)$ & $(2.84)$ \\
\hline \multirow[t]{2}{*}{ Constant } & $0.9812^{* *}$ & $1.1012^{* * *}$ & $0.7021^{*}$ & $1.2934^{* * *}$ \\
\hline & (1.99) & $(2.60)$ & $(1.71)$ & $(2.90)$ \\
\hline Individual FE & Yes & Yes & YES & \\
\hline Time FE & Yes & YES & YES & \\
\hline AR (2)-P & & & & 0.28 \\
\hline Obs. & 240 & 224 & 208 & 224 \\
\hline
\end{tabular}

Notes: t-statistics are in parentheses; ${ }^{*},{ }^{* * * *}$ stand for significance at $10 \%, 5 \%, 1 \%$, respectively; P value of AR (2) indicates no second-order correlation.

\subsubsection{Dynamic threshold model results}

In this section, we proceed to estimate the threshold model to check the nonlinear effect of urban agglomeration spatial structural evolution on green economy, through which we can further examine the validation of spatial structure's effect on green economy, and enable us to clearly understand whether the polycentric spatial structure or monocentric one performs better for the green economy. To check the threshold effect, we use the bootstrap-based testing procedure to obtain an approximation of the F-statistics and P-values. For each of the bootstrap tests, 500 bootstrap replications are used. As shown in Table 3, for the monocentric index, F statistics are significant at least $10 \%$ level for single threshold, double thresholds and triple thresholds, indicating that there are three thresholds, which probably brings structural breaks and different effects varies across scenarios. The results indicate that there are at least three thresholds in the relationship between monocentric index and green economy, implying that the green economy is sensitive to the urban agglomeration spatial structural evolution. In other words, different ranges of spatial structure matter significantly in affecting green economy. 
Table 3. Test of threshold effect: number for threshold and threshold value

\begin{tabular}{cccccc}
\hline Explained variable & Threshold variable & Number for threshold & Threshold value & F-value & P-value \\
\hline & & 1 & 0.9671 & 2.8959 & 0.0990 \\
Green economy & Monocentric index & 2 & $0.8436,0.9671$ & 9.9130 & 0.0040 \\
& & 3 & $0.8436,0.9671,1.5849$ & 3.3797 & 0.0710 \\
\hline
\end{tabular}

Table 4 shows the coefficients for the monocentric index. As can be seen, when monocentric index $\leq 0.8436$, coefficient of monocentric index to green economy is -0.9206 ; when $0.8436<$ monocentric index $\leq 0.9671$, coefficient value is -0.6322 ; when $0.9671<$ monocentric index $\leq 1.5849$, coefficient value is -0.8854 , when monocentric index $>1.5849$, coefficient value is -0.8037 , meantime, such four coefficients are all statistically significant at the 1\% level. Overall, for urban agglomerations, different monocentric index ranges exert different impacts on green economy, as the monocentric index value increases, its effects on green economy vary. When $0.8436<$ monocentric index $\leq 0.9671$, the monocentric index exerts the best impact on green economy, indicating that a polycentric urban agglomeration (i.e., when the monocentric index is 0.8436 0.9671, an urban agglomeration can be regarded as polycentric according to the Pareto exponent) is more conducive to the green economic growth.

Table 4. Threshold regression results: test for green economy

\begin{tabular}{cc} 
Variables & Coefficients \\
\hline GE $(-1)$ & $0.5106^{* * *}(3.42)$ \\
Mono $1($ mono $\leq 0.8436)$ & $-0.9206^{* * *}(-3.26)$ \\
Mono·1 $(0.8436<$ mono $\leq 0.9671)$ & $-0.6322^{* * *}(-2.65)$ \\
Mono·1 $(0.9671<$ mono $\leq 1.5849)$ & $-0.8854^{* * *}(-4.24)$ \\
Mono·1(mono $>1.5849)$ & $-0.8037^{* * *}(-4.44)$ \\
FDI & $-0.2632^{* * *}(-3.39)$ \\
Urbanization & $0.1345^{* * *}(11.13)$ \\
R\&D & $4.5233^{* * *}(6.71)$ \\
\hline
\end{tabular}

Notes: t-statistics are in parentheses; ${ }^{* * *},{ }^{* * *}$ stand for significance at $10 \%, 5 \%, 1 \%$, respectively.

From the above analysis, we can see that: there is a non-linear relationship between the spatial structure and the green economy of urban agglomerations; different stages of spatial structure 
evolution have different effects on the green economy; on the whole, there is an optimal spatial structure to promote green economic growth in urban agglomerations. Then, from the perspective of promoting green economic growth, among the 16 urban agglomerations, which urban agglomerations have always been in the optimal spatial structure? which ones are gradually moving away from the optimal spatial structure? and which ones are gradually approaching the optimal spatial structure? To address these queries, we draw Fig. 5. In the figure, the dots are the trajectories of the monocentric index of 16 urban agglomerations from 2003 to 2017, and the two horizontal blue dotted lines are the optimal range for achieving green economy. The optimal range is obtained through the threshold regression model results (see section 3.1.2). From the Fig. 5, three main findings are shown below: (1) During 2003-2017, five urban agglomerations are very close to the optimal range, such as Pearl River Delta, Mid-southern Liaoning urban agglomerations; (2) Some urban agglomerations tend to be far from the optimal range. Such as Guanzhong and Beibu-Gulf urban agglomerations; (3) Some urban agglomerations are moving towards the optimal range, but there is still much room for improvement, such as Jinzhong, Cheng-yu and Hu-Bao-E-Yu urban agglomerations. In short, during the study period, the positive effect of the evolution of the spatial structure of Chinese urban agglomerations on green economy has not been fully stimulated.

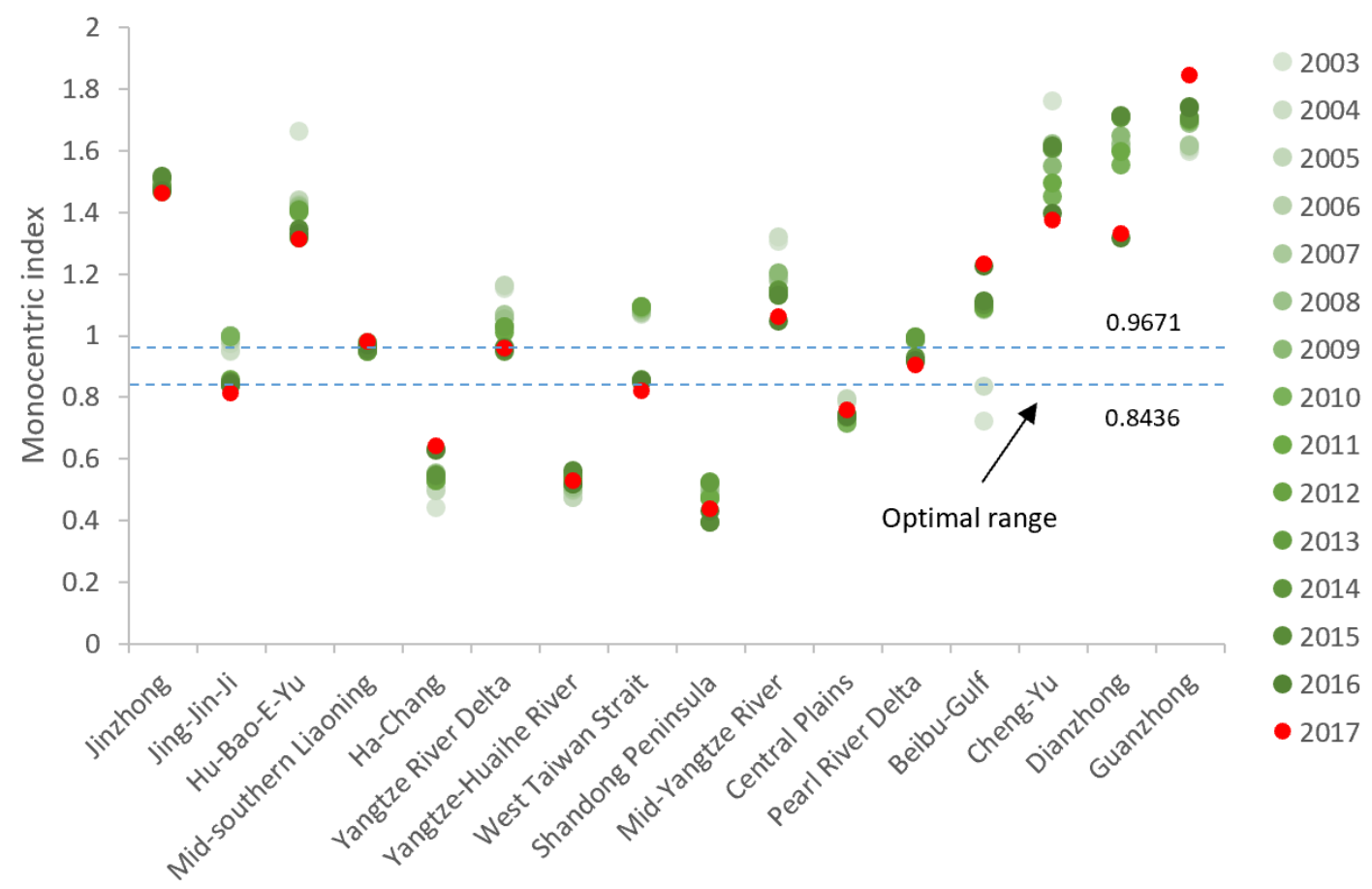

Fig. 5. Spatial structure evolution (distribution of monocentric index) for 16 urban agglomerations from 2003 to 2017 and the optimal spatial structure range for green economy 


\subsection{Empirical results 2: How does spatial structure affect the three subsystems in green economy}

\subsubsection{Baseline linear model results}

Now, we proceed with our paper for retailed research about the three subsystems. Resemble the full sample regression (section 3.1), we begin with the linear regression.

To ensure a robust result, for each subsystem, we make three regressions, i.e., no-lagged independent variable, one-lagged independent variable and two-lagged independent variable based on the baseline linear model, respectively. Corresponding results are shown in Table 5. Specifically, as shown in columns (1)-(3), the variable monocentric index is negatively correlated with economic subsystem at least $5 \%$ level, indicating that the increase in monocentric index in urban agglomerations constrains the economic growth, which verifies that the tendency to monocentric will not contribute to the improvement in economic growth, such conclusion is in line with previous study (Hou and Sun, 2016). Coefficients in columns (4)-(6) witness the negative relationship between monocentric index and resources subsystem, indicating that a $1 \%$ increase in monocentric index brings $0.0504 \% \sim 0.0755 \%$ decrease in resources subsystem, which also implies that the trend to monocentric does not benefit the resource utilization. As for the effect of monocentric index on environmental subsystem, from the positive coefficients in columns (7)-(9), we argue that, unlike the other two declarations, increase in monocentric index is positively correlated with the environmental protection, implying that the increase in monocentric index may benefit the environmental protection in some degree.

Table 5. Regression results for three subsystems: linear model

\begin{tabular}{|c|c|c|c|c|c|c|c|c|c|}
\hline & \multicolumn{3}{|c|}{ Economic subsystem } & \multicolumn{3}{|c|}{ Resources subsystem } & \multicolumn{3}{|c|}{ Environmental subsystem } \\
\hline & (1) & (2) & (3) & (4) & (5) & (6) & (7) & (8) & (9) \\
\hline & No lag & One-lag & Two-lag & No lag & One-lag & Two-lag & No lag & One-lag & Two-lag \\
\hline \multirow[t]{2}{*}{ Mono } & $-0.7291^{* * * *}$ & & & $-0.0755^{* * *}$ & & & 0.0059 & & \\
\hline & $(-3.69)$ & & & $(-2.89)$ & & & (1.18) & & \\
\hline \multirow[t]{2}{*}{ Mono (-1) } & & $-0.5943^{* * *}$ & & & $-0.0504^{*}$ & & & $0.0061^{*}$ & \\
\hline & & $(-3.04)$ & & & $(-1.91)$ & & & (1.75) & \\
\hline \multirow[t]{2}{*}{ Mono (-2) } & & & $-0.3991^{* *}$ & & & $-0.0593^{* *}$ & & & 0.0052 \\
\hline & & & $(-2.40)$ & & & $(-2.01)$ & & & (1.01) \\
\hline
\end{tabular}




\begin{tabular}{|c|c|c|c|c|c|c|c|c|c|}
\hline FDI & $-0.2580^{* *}$ & $-0.3144^{* *}$ & $-0.2802^{* * *}$ & $-0.0113^{*}$ & $-0.0181^{* *}$ & $-0.0236^{*}$ & $0.0047^{* *}$ & 0.0164 & $0.061^{* *}$ \\
\hline \multirow{3}{*}{ Urbanization } & $(-2.45)$ & $(-2.42)$ & $(-4.06)$ & $(-1.77)$ & $(-2.01)$ & $(-1.93)$ & $(2.04)$ & $(0.77)$ & $(2.07)$ \\
\hline & $0.0964^{* * *}$ & $0.1026^{* * *}$ & -0.0232 & $0.0210^{* * *}$ & -0.0026 & -0.0036 & 0.0028 & 0.0027 & $0.0042^{*}$ \\
\hline & $(4.32)$ & $(4.93)$ & $(-0.62)$ & $(6.79)$ & $(-0.45)$ & $(-0.52)$ & $(0.97)$ & $(0.47)$ & (1.66) \\
\hline \multirow[t]{2}{*}{$R \& D$} & $3.0911^{* * *}$ & $4.0462^{* * *}$ & 1.2394 & $0.5658^{* * *}$ & $0.2588^{*}$ & $0.2492^{*}$ & $0.5422^{* * *}$ & $0.4501^{* *}$ & $0.4947^{* * *}$ \\
\hline & (4.19) & $(5.06)$ & (1.60) & $(3.81)$ & (1.76) & $(1.72)$ & $(3.78)$ & $(2.24)$ & (3.54) \\
\hline \multirow[t]{2}{*}{ Constant } & $-1.0112^{* * *}$ & $-1.2734^{* * *}$ & 0.6320 & $-0.2042^{* * *}$ & 0.1063 & 0.0871 & $0.2151^{* * *}$ & $0.2612^{* * *}$ & $0.1867^{* * *}$ \\
\hline & $(-2.81)$ & $(-3.13)$ & $(1.20)$ & $(-3.53)$ & (1.48) & (1.14) & (6.37) & $(3.45)$ & $(6.15)$ \\
\hline Individual FE & Yes & Yes & Yes & Yes & Yes & Yes & Yes & Yes & Yes \\
\hline Time FE & Yes & Yes & Yes & Yes & Yes & Yes & Yes & Yes & Yes \\
\hline Obs. & 240 & 224 & 208 & 240 & 224 & 208 & 240 & 224 & 208 \\
\hline R-squared & 0.8353 & 0.8490 & 0.9287 & 0.8976 & 0.9291 & 0.9255 & 0.9344 & 0.9413 & 0.9011 \\
\hline
\end{tabular}

Notes: t-statistics are in parentheses; ${ }^{*},{ }^{* *},{ }^{* * *}$ stand for significance at $10 \%, 5 \%, 1 \%$, respectively.

\subsubsection{Dynamic threshold model results}

Next, we explore the threshold regression to check the possible nonlinear effects for better insights

391 in seeking the effects of spatial structural evolution on the three subsystems.

Table 6 demonstrates the test of threshold effect, the $F$ statistics are all significant for single 393 threshold, double thresholds and triple thresholds. It is evident that the effects of spatial structure evolution on the three subsystems are sensitive to the changes in monocentric index.

Table 6. Test of threshold effect: number for threshold and threshold value

\begin{tabular}{cccccc}
\hline Dependent variable & Threshold variable & Number for threshold & Threshold value & F-value & P-value \\
\hline \multirow{2}{*}{ Economic subsystem } & 1 & 0.9671 & 5.3455 & 0.0170 \\
& & 2 & $0.8436,0.9671$ & 10.7188 & 0.0010 \\
& Monocentric index & 3 & $0.8436,0.9671,1.5849$ & 7.4490 & 0.0030 \\
Resources subsystem & 1 & 0.8548 & 7.3440 & 0.0110 \\
& 2 & $0.8548,0.9784$ & 7.1175 & 0.0140 \\
Environmental subsystem & 3 & $0.8548,0.9784,1.4614$ & 3.3601 & 0.0180 \\
\hline
\end{tabular}




\begin{tabular}{cccc} 
& $0.5964,1.0907$ & 8.1854 & 0.0030 \\
3 & $0.5964,1.0907,1.2148$ & 5.9842 & 0.0210 \\
\hline
\end{tabular}

396

Table 7 illustrates the estimated regression coefficients for the three subsystems one by one. First, for the economic subsystem, all the regression coefficients are statistically significant. Specifically, when monocentric index $\leq 0.8436$, coefficient of monocentric index to economic subsystem is -0.8759 ; when $0.8436<$ monocentric index $\leq 0.9671$, coefficient value is -0.5949 ; when $0.9671<$ monocentric index $\leq 1.5849$, coefficient value is -0.8628 ; when monocentric index $>1.5849$, coefficient value is -0.7574 ; Overall, for urban agglomerations, different monocentric index ranges exert different impacts on economic subsystem, as the monocentric index value increases, its effects on economic subsystem vary. When $0.8436<$ monocentric index $\leq 0.9671$, the monocentric index exerts the best impact on economic subsystem. It indicates that a polycentric urban agglomeration (the monocentric index 0.8436 0.9671) is more conducive to the economic growth.

Second, for the resources subsystem, when monocentric index $\leq 0.8548$, coefficient of monocentric index to resource subsystem is -0.0726 ; when $0.8548<$ monocentric index $\leq 0.9784$, coefficient value is -0.0621 ; when $0.9784<$ monocentric index $\leq 1.4614$, coefficient value is -0.0803 , when monocentric index $>1.4614$, coefficient value is 0.0209 , but not statistically significant. When $0.8548<$ monocentric index $\leq 0.9784$, the monocentric index exerts the best impact on resources subsystem, implying that a polycentric urban agglomeration (the monocentric index $0.8548 \sim 0.9784$ ) is more conducive to the resources utility.

Third, for the environmental subsystem, when monocentric index $\leq 0.5964$, coefficient of monocentric index to green economy is -0.076; after the monocentric index exceeds the threshold value 0.5964, coefficient is insignificant any more, but vary from negative to positive, when monocentric index $>1.2143$, coefficient value is 0.0288 at the $10 \%$ significance level, indicating a positive correlation between the monocentric index and the environmental subsystem. It also implies that a polycentric urban agglomeration spatial structure probably triggers the pollution emissions. Similar findings could be found in existing papers, such as polycentricity is significantly positively correlated with $\mathrm{CO} 2$, PM2.5 and PM10, polycentricity alone does not reduce pollution emissions (Burgalassi and Luzzati, 2015; Liu et al., 2020). 
Table 7. Test for threshold effect: regression results

\begin{tabular}{|c|c|c|c|c|c|}
\hline \multicolumn{2}{|c|}{ Economic subsystem } & \multicolumn{2}{|c|}{ Resources subsystem } & \multicolumn{2}{|c|}{ Environmental subsystem } \\
\hline Threshold variable & coefficients & Threshold variable & coefficients & Threshold variable & coefficients \\
\hline \multirow{3}{*}{ Mono $\cdot 1($ mono $\leq 0.8436)$} & $-0.8759^{* * *}$ & & $-0.0726^{*}$ & \multirow{3}{*}{ Mono $\cdot 1($ mono $\leq 0.5964)$} & $-0.0076^{*}$ \\
\hline & & Mono $\cdot 1($ mono $\leq 0.8548)$ & & & \\
\hline & $(-3.52)$ & & $(-1.95)$ & & $(-1.73)$ \\
\hline Mono $\cdot 1(0.8436<$ & $-0.5949^{* * *}$ & Mono $\cdot 1(0.8548<$ & $-0.0621^{* *}$ & Mono $\cdot 1(0.5964<$ & -0.0143 \\
\hline mono $\leq 0.9671)$ & $(-2.86)$ & mono $\leq 0.9784)$ & $(-2.19)$ & mono $\leq 1.0907)$ & $(-0.45)$ \\
\hline Mono $\cdot 1(0.9671<$ & $-0.8628^{* * *}$ & Mono $\cdot 1(0.9784<$ & $-0.0803^{* *}$ & Mono $\cdot 1(1.0907<$ & 0.0047 \\
\hline mono $\leq 1.5849$ ) & $(-4.76)$ & mono $\leq 1.4614)$ & $(-2.26)$ & $\operatorname{mono} \leq 1.2143)$ & $(0.18)$ \\
\hline Mono $\cdot 1$ (mono $>$ & $-0.7574^{* * *}$ & Mono $\cdot 1$ (mono $>$ & 0.0209 & Mono $\cdot 1$ (mono $>$ & $0.0288^{*}$ \\
\hline 1.5849$)$ & $(-4.97)$ & 1.4614) & $(0.66)$ & $1.2143)$ & $(1.83)$ \\
\hline
\end{tabular}

424

Notes: $z$-statistics are in parentheses; ${ }^{*},{ }^{* *},{ }^{* * *}$ stand for significance at $10 \%, 5 \%, 1 \%$, respectively; coefficients of control variables and one-lag of explained variables of the three subsystems are not shown, and available on request.

In summary, based on the results of linear and nonlinear models, we get the following main findings: (1) Although the polycentric spatial structure shows better performance than the monocentric spatial structure in terms of promoting the green economy in urban agglomerations, polycentric spatial structure does not always boost the development of green economy. In other words, excessively polycentric spatial structure will constrain the green economy; (2) Promoting the green economy requires the coordinated improvement of the three subsystems of economy, resources, and environment. However, it can be seen from the findings that the impact of spatial structural evolution (i.e., the change of monocentric index) on the environmental subsystem is not like the economic and resources subsystems, i.e., to get a better performance of economic growth and efficient resources utility, the polycentric spatial structure of urban agglomeration is prior to the monocentric one; whereas, to achieve a better performance of environmental protection and pollution control, the monocentric spatial structure seems to be the first choice rather than the polycentric one. Therefore, to promote green economic growth through the construction of urban agglomerations, it is necessary to comprehensively consider multiple aspects. Urban agglomerations should not simply follow a monocentric spatial structure or a polycentric spatial structure. 


\section{Concluding remarks}

Understanding whether and how urban agglomeration spatial structure affect green economy is of great importance for exploring the growth effects of urban agglomeration. Exploring such issues could reveal whether urban agglomeration achieve economic growth, resources saving and environmental protection simultaneously? However, as of now, theoretical and empirical evidence regarding to this has not received strong supports. To bridge this gap, our paper conducts a comprehensive study to shed light on how the evolution of urban agglomeration spatial structure affects the green economy.

The conclusions of the linear model compared with the dynamic threshold model that we employ in this paper reveal differences in assessing spatial structure's effect on the green economy. This means that the linear model does not capture the nonlinear effects stemmed from the existence of the differentiated spatial structure ranges, therefore, the threshold model is probably the better econometric model to evaluate the spatial structure's influence on the green economy. Specifically, our findings not only support the existing studies, but also have new discoveries, which are also further improvements to the existing papers. First of all, we use a general linear model to conclude that the tend to polycentric spatial structure of urban agglomerations are beneficial to green economic growth. Further, the non-linear regression model we adopt reveals that although it can be clearly known from the linear regression results that the polycentric trend is conducive to the development of green economy, there is an optimal range in polycentric spatial structure. In other words, higher polycentric value does not necessarily mean a better green economy performance. Thus, through the findings, our paper improves the conclusions in the existing linear regression literature.

Some concluding remarks are given below. First, in general, towards polycentric is contributive to green economy, while the excessive polycentric could not benefit the green economic growth. From the perspective of economic growth and resource intensive utilization, a polycentric urban spatial distribution should be constructed so as to avoid the excessive concentration of resources and the reduction of resource efficiency caused by the dominance of one central/large city. However, excessive polycentricity may also lead to the loss of economic efficiency and resource utilization, and hinder the green economic growth. In particular, we also find that, from the perspective of achieving better environmental protection quality and urban pollution control, the urban agglomerations stylized by monocentric have comparative advantages than polycentric ones. Therefore, the construction of urban 
agglomerations should not weaken the status and hierarchy of core cities. On the contrary, it is still very important to consolidate the status of existing core cities. In summary, for a certain urban agglomeration, its spatial structure is relatively stable, therefore, the policymakers should give enough considerations to this to avoid a policy bias. In other words, since the spatial structure of urban agglomerations is not easy to adjust in the short term, it is necessary to demonstrate as clearly as possible which choice the urban agglomerations prefer in next stage: economic growth, resource conservation or pollution control? For instance, for urban agglomerations with more developed economy but relatively serious pollution, the monocentric index can be appropriately increased to obtain better pollution abatement; while for urban agglomerations with relatively backward economy but higher environmental quality, the monocentric index can be moderately reduced (i.e., towards the polycentric spatial structure) to enhance the flow of factors of production and the market competition, and thereby to speed up the economic development and expand the economic size. These are probably conducive to driving the green economy of urban agglomerations.

Second, most urban agglomerations in China are not currently in the optimal spatial structure ranges for green economic growth. The spatial structural evolution of urban agglomerations presents obvious heterogeneous characteristics, and the monocentric index of some urban agglomerations has experienced two different trajectories (far away or close to the optimal range). Therefore, it is necessary to formulate a reasonable urban agglomeration spatial pattern according to its own development level or stage, so as to towards the green economy.

This paper leaves some unaddressed issues for future research. it only presents the relationship between urban agglomeration spatial structure and green economy. However, the mechanism behind the empirical results is still not fully clear and needs thorough examination in future study. Another limitation is in the miss of some useful indicators because of the inefficient data collection, just as asserted by Verma and Raghubanshi (2018), application of indicators and subsequent assessment of urban sustainability will be most influenced by data availability. For example, the green patent, which is probably treated as a valuable indicator for assessing green economy, is forced to dropped because of the missing data in official database. Lastly, evaluating the green economy performance is not easy owing to its dynamic and complicated feature, just as noted by Benson et al. (2021), "meanings of the green economy changes in a changing world". Although in this paper we endeavor to overcome this to towards a better research, some unchecked or unobserved aspects are out of our sightseeing. 


\section{Declarations}

501 Authors' contributions The idea and original writing for the article are conducted by Yue Huang; 502 Organization, critical feedback and supervision are made from Ruiwen Liao, All authors have read and 503 approved the manuscript.

Funding We would like to thank the National Social Science Fund (18BJL049), National Social Science Fund (20XJL009), Guangxi Social Science Fund (20FJY008) for their supports.

Availability of data and materials Available upon request.

Ethics approval and consent to participate Not applicable.

Consent for publication Not applicable.

Competing interests The authors declare no competing interests.

\section{References}

Abid, N., Ikram, M., Jianzu, W., Ferasso, M. (2021). Towards environmental sustainability: Exploring the nexus among ISO 14001, governance indicators and green economy in Pakistan. Sustainable Production and Consumption, 27, 653-666.

Arellano, M., Bond, S. (1991). Some Tests of Specification for Panel Data: Monte Carlo Evidence and an Application to Employment Equations. The Review of Economic Studies, 58(2), 277-297.

Benson, D., Fairbrass, J. M., Lorenzoni, I., O'Riordan, T., Russel, D. (2021). The green economy: changing meanings in a changing world. Emerging Governance of a Green Economy, 14-33.

Blundell, R., Bond, S. R. (1998). Initial conditions and moment restrictions in dynamic panel data models. Journal of Econometrics, 87(1), 115-143.

Burgalassi, D., Luzzati, T. (2015). Urban spatial structure and environmental emissions: a survey of the literature and some empirical evidence for Italian NUTS-3 regions. Cities, 49, 134-148.

Carroll, Z., Couzo, E. (2021). Should North Carolina require more efficient water heaters in homes? A cost-benefit analysis. Energy Policy, 150, 112113.

Clark, L. P., Millet, D. B., Marshall, J. D. (2011). Air quality and urban form in U.S. urban areas: evidence 
from regulatory monitors. Environmental Science \& Technology, 45(16), 7028-7035.

D’amato, D., Droste, N., Allen, B., Kettunen, M., Lähtinen, K., Korhonen, J., Toppinen, A. (2017). Green, circular, bio economy: A comparative analysis of sustainability avenues. Journal of Cleaner Production, 168, 716-734.

D’amato, D., Droste, N., Winkler, K., Toppinen, A. (2019b). Thinking green, circular or bio: Eliciting researchers' perspectives on a sustainable economy with Q method. Journal of Cleaner Production, 230, 460-476.

D’Amato, D., Korhonen, J., Toppinen, A. (2019a). Circular, green, and bio economy: how do companies in land-use intensive sectors align with sustainability concepts? Ecological Economics, 158, 116-133.

Espezua, S., Villanueva, E., Maciel, C. D. (2014). Towards an efficient genetic algorithm optimizer for sequential projection pursuit. Neurocomputing, 123, 40-48.

Fang, C. (2015). Important progress and future direction of studies on China's urban agglomerations. Journal of Geographical Sciences, 25(8), 1003-1024.

Fang, C., Zhou, C., Gu, C., Chen, L., Li, S. (2017). A proposal for the theoretical analysis of the interactive coupled effects between urbanization and the eco-environment in mega-urban agglomerations. Journal of Geographical Sciences, 27(12), 1431-1449.

Finnveden, G., Hauschild, M. Z., Ekvall, T., Guinée, J. B., Heijungs, R., Hellweg, S., Suh, S. (2009). Recent developments in life cycle assessment. Journal of Environmental Management, 91(1), 1-21.

Garcia-López, M. À., Muñiz, I. (2012). Urban spatial structure, agglomeration economies, and economic growth in Barcelona: An intra-metropolitan perspective. Papers in Regional Science, 92(3), 515-534.

Glaeser, E. L., Kahn, M. E., 2010. The greenness of cities: carbon dioxide emissions and urban development. Journal of Urban Economics, 67(3), 404-418.

Gregorio, V. F., Pié, L., Terceño, A. (2018). A systematic literature review of bio, green and circular economy trends in publications in the field of economics and business management. Sustainability, $10(11), 4232$.

Gupta, M. K., Song, Q., Liu, Z., Pruncu, C. I., Mia, M., Singh, G., .. Jamil, M. (2020). Machining characteristics based life cycle assessment in eco-benign turning of pure titanium alloy. Journal of Cleaner Production, 251, 119598.

Haider, H., Hewage, K., Umer, A., Ruparathna, R., Chhipi-Shrestha, G., Culver, K., Sadiq, R. (2018). 
Sustainability assessment framework for small-sized urban neighborhoods: An application of fuzzy synthetic evaluation. Sustainable Cities and Society, 36, 21-32.

Han, S., Sun, B., Zhang, T. (2020). Mono- and polycentric urban spatial structure and PM2.5 concentrations: Regarding the dependence on population density. Habitat International, 104, 102257.

Hankey, S., Marshall, J. D. (2017). Urban form, air pollution, and health. Current Environmental Health Reports, 4(4), 491-503.

Hansen, B. E. (1999). Threshold effects in non-dynamic panels: Estimation, testing, and inference. Journal of Econometrics, 93(2), 345-368.

Hansen, B. E. (2000). Sample splitting and threshold estimation. Econometrica, 68(3), 575-603.

Hoogmartens, R., Passel, S. V., Acker, K. V., Dubois, M. (2014). Bridging the gap between LCA, LCC and CBA as sustainability assessment tools. Environmental Impact Assessment Review, 48, 27-33.

Hou, Y., Sun, T. (2016). Economic performance of spatial structure of urban agglomerations in China: Empirical analysis based on panel data. Exploration of Economic Issue, 2, 80-88.

Huang, C., Liu, K., Zhou, L. (2021). Spatio-temporal trends and influencing factors of PM2.5 concentrations in urban agglomerations in China between 2000 and 2016. Environmental Science and Pollution Research, 28, 10988-11000.

Huang, J., Liu, Q., Cai, X., Hao, Y., Lei, H., 2018. The effect of technological factors on China's carbon intensity: New evidence from a panel threshold model. Energy Policy, 115, 32-42.

Konisky, D. M., Woods, N. D. (2010). Exporting air pollution? regulatory enforcement and environmental free riding in the United States. Political Research Quarterly, 63(4), 771-782.

Kremer, S., Bick, A., Nautz, D. (2013). Inflation and growth: new evidence from a dynamic panel threshold analysis. Empirical Economics, 44(2), 861-878.

Lau, L. S., Choong, C. K., Eng, Y. K., 2014. Investigation of the environmental Kuznets curve for carbon emissions in Malaysia: do foreign direct investment and trade matter? Energy Policy, 68, 490-497.

Lee, S., Lee, B. (2020). Comparing the impacts of local land use and urban spatial structure on household VMT and GHG emissions. Journal of Transport Geography, 84, 102694.

Li, B., Wu, S. (2017). Effects of local and civil environmental regulation on green total factor productivity in China: A spatial Durbin econometric analysis. Journal of Cleaner Production, 153, 342-353. 
Li, J., Wang, R., Li, H., Nie, Y., Song, X., Li, M., .. Wang, C. (2021). Unit-level cost-benefit analysis for coal power plants retrofitted with biomass co-firing at a national level by combined GIS and life cycle assessment. Applied Energy, 285, 116494.

Li, W., Sun, B., Zhang, T. (2019). Spatial structure and labor productivity: Evidence from prefectures in China. Urban Studies, 56(8), 1516-1532.

Li, W., Sun, B., Zhao, J., Zhang, T. (2018). Economic performance of spatial structure in Chinese prefecture regions: Evidence from night-time satellite imagery. Habitat International, 76, 29-39.

Liu, K., Wu, Y., Wang, X., Wang, C. (2020). Impact of spatial structure of urban agglomerations on air pollution in China. China Population, Resources and Environment, 30(10), 28-35.

Liu, K., Xue, M., Peng, M., Wang, C. (2020). Impact of spatial structure of urban agglomeration on carbon emissions: An analysis of the Shandong Peninsula, China. Technological Forecasting and Social Change, 161, 120313.

Liu, X., Li, S., Qin, M. (2017b). Urban spatial structure and regional economic efficiency, Journal of Management World, 1, 51-64.

Liu, X., Song, L., Chen, Z. (2017a). Polycentric development and its effect on regional income disparity. China Industrial Economics, 10, 25-43.

Loiseau, E., Saikku, L., Antikainen, R., Droste, N., Hansjürgens, B., Pitkänen, K., Thomsen, M. (2016). Green economy and related concepts: An overview. Journal of Cleaner Production, 139, 361-371.

Meijers, E. (2008). Measuring polycentricity and its promises. European Planning Studies, 16(9), 1313-1323.

Meijers, E. J., Burger, M. J. (2010). Spatial structure and productivity in US metropolitan areas. Environment and Planning A, 42(6), 1383-1402.

Merino-Saum, A., Baldi, M. G., Gunderson, I., Oberle, B. (2018). Articulating natural resources and sustainable development goals through green economy indicators: A systematic analysis. Resources Conservation and Recycling, 139, 90-103.

Miao, Z., Chen, X., Baležentis, T. (2021). Improving energy use and mitigating pollutant emissions across "Three Regions and Ten Urban Agglomerations": A city-level productivity growth decomposition. Applied Energy, 283, 116296.

Miao, Z., Chen, X., Baležentis, T., Sun, C. (2019). Atmospheric environmental productivity across the provinces of China: Joint decomposition of range adjusted measure and Luenberger productivity 
indicator. Energy Policy, 132, 665-677.

Muñiz, I., Garcia-López, M.-À. (2019). Urban form and spatial structure as determinants of the ecological footprint of commuting. Transportation Research Part D-Transport and Environment, 67, 334-350.

Muñiz, I., Sánchez, V. (2018). Urban spatial form and structure and greenhouse-gas emissions from commuting in the metropolitan zone of Mexico Valley. Ecological Economics, 147, 353-364.

Nijman, J., Wei, Y. D. (2020). Urban inequalities in the 21st century economy. Applied Geography, 117, 102188.

Omri, A., Nguyen, D. K., Rault, C., 2014. Causal interactions between CO2 emissions, FDI, and economic growth: Evidence from dynamic simultaneous-equation models. Economic Modelling, 42, 382-389.

Owsianiak, M., Lindhjem, H., Cornelissen, G., Hale, S. E., Sørmo, E., Sparrevik, M. (2021). Environmental and economic impacts of biochar production and agricultural use in six developing and middle-income countries. Science of The Total Environment, 755, 142455.

Pan, W., Pan, W., Hu, C., Tu, H., Zhao, C., Yu, D., Zheng, G. (2019). Assessing the green economy in China: An improved framework. Journal of Cleaner Production, 209, 680-691.

Pearce, D. W., Markandya, A., Barbier, E. (1989). Blueprint for a green economy. Earthscan, London, Great Britain.

Ringel, M., Schlomann, B., Krail, M., Rohde, C. (2016). Towards a green economy in Germany? The role of energy efficiency policies. Applied Energy, 179, 1293-1303.

Röck, M., Saade, M. R. M., Balouktsi, M., Rasmussen, F. N., Birgisdottir, H., Frischknecht, R., ... Passer, A. (2020). Embodied GHG emissions of buildings - The hidden challenge for effective climate change mitigation. Applied Energy, 258, 114107.

Seo, M. H., Shin, Y. (2016). Dynamic panels with threshold effect and endogeneity. Journal of Econometrics, 195(2), 169-186.

Sigman, H. (2005). Transboundary spillovers and decentralization of environmental policies. Journal of Environmental Economics and Management, 50(1), 82-101.

Söderqvist, T., Brinkhoff, P., Norberg, T., Rosén, L., Back, P.-E., Norrman, J. (2015). Cost-benefit analysis as a part of sustainability assessment of remediation alternatives for contaminated land. Journal of Environmental Management, 157, 267-278. 
Tian, Y., Sun, C. (2018). Comprehensive carrying capacity, economic growth and the sustainable development of urban areas: A case study of the Yangtze River Economic Belt. Journal of Cleaner Production, 195, 486-496.

Vandermotten, C., Halbert, L., Roelandts, M., Cornut, P. (2008). European planning and the polycentric consensus: Wishful thinking? Regional Studies, 42(8), 1205-1217.

Verma, P., Raghubanshi, A. S. (2018). Urban sustainability indicators: Challenges and opportunities. Ecological Indicators, 93, 282-291.

Wang, G., Deng, X., Wang, J., Zhang, F., Liang, S. (2019). Carbon emission efficiency in China: A spatial panel data analysis. China Economic Review, 56, 101313.

Wang, M., Zhao, X., Gong, Q., Ji, Z. (2019). Measurement of regional green economy sustainable development ability based on entropy weight-Topsis-coupling coordination degree-A Case Study in Shandong Province, China. Sustainability, 11(1), 280.

Wang, S., Wang, H., Zhang, L., Dang, J. (2019). Provincial carbon emissions efficiency and its influencing factors in China. Sustainability, 11(8), 2355.

Wei, P., Fu, Q., Liu, D., Li, T., Cheng, K. (2016). Assessing agricultural drought vulnerability in the Sanjiang Plain based on an improved projection pursuit model. Natural Hazards, 82(1), 683-701.

Wu, M., Wu, J., Zang, C. (2021). A comprehensive evaluation of the eco-carrying capacity and green economy in the Guangdong-Hong Kong-Macao Greater Bay Area, China. Journal of Cleaner Production, 281, 124945.

Xie, M., Wang, J., Chen, K. (2016). Coordinated development analysis of the "resources-environment-ecology-economy-society" complex system in China. Sustainability, 8(6), $1-23$.

Zhang, N., Yu, K., Chen, Z., 2017. How does urbanization affect carbon dioxide emissions? A cross-country panel data analysis. Energy Policy, 107, 678-687.

Zhang, T., Sun, B., Li, W. (2017). The economic performance of urban structure: From the perspective of Polycentricity and Monocentricity. Cities, 68, 18-24.

Zhang, X., Shen, J., Wang, Y., Qi, Y., Liao, W., Shui, W., Yu, X. (2017). An environmental sustainability assessment of China's cement industry based on emergy. Ecological Indicators, 72, 452-458.

Zhang, Y., Su, Z., Li, G., Zhuo, Y., Xu, Z. (2018). Spatial-temporal evolution of sustainable urbanization development: A perspective of the coupling coordination development based on population, 
industry, and built-up land spatial agglomeration. Sustainability, 10(6), 1766.

677 Zhou, L. (2007). Governing China's local officials: An analysis of promotion tournament model. Economic Research Journal, 7, 36-50. 
Figures

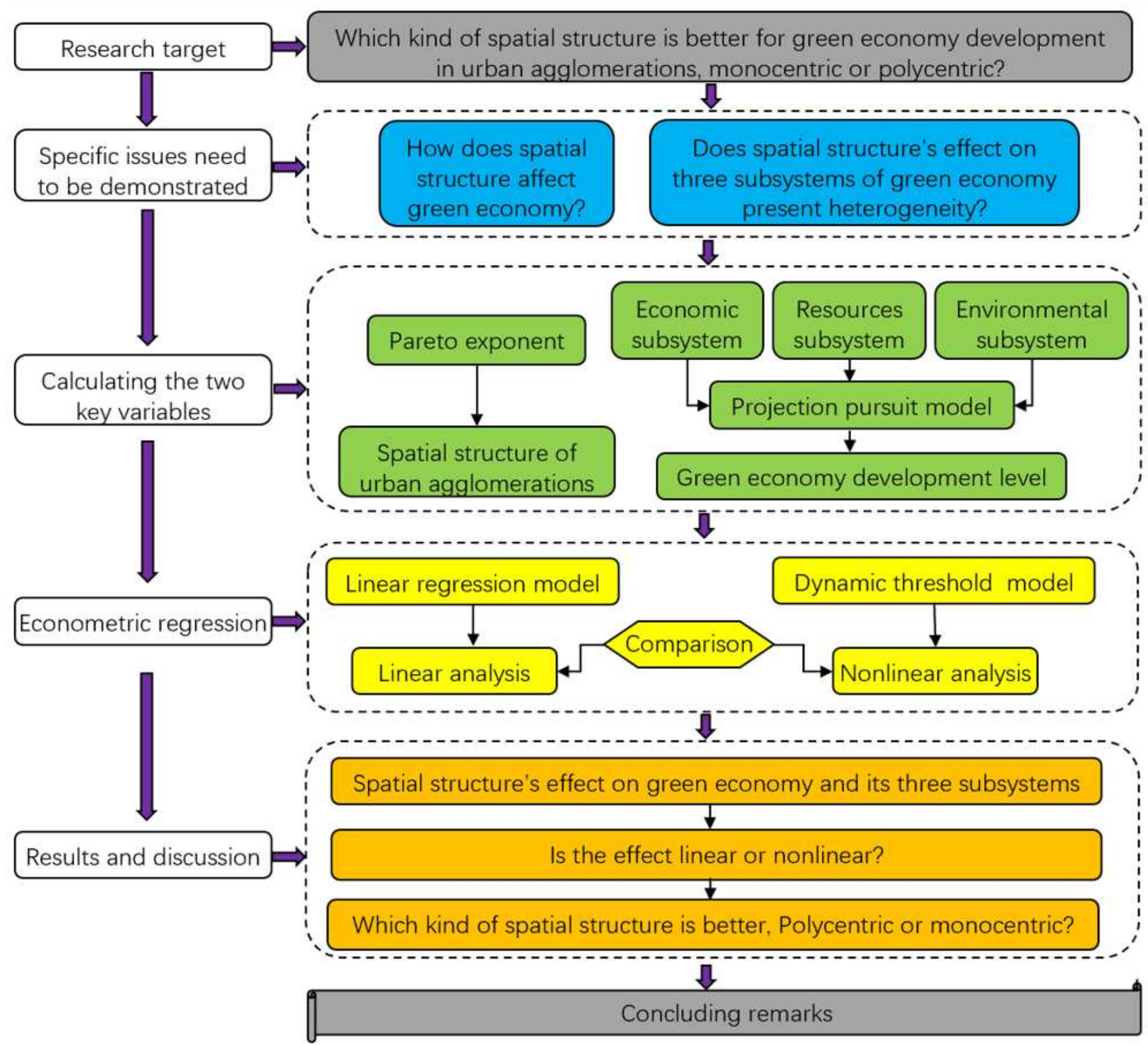

Figure 1

Research framework 


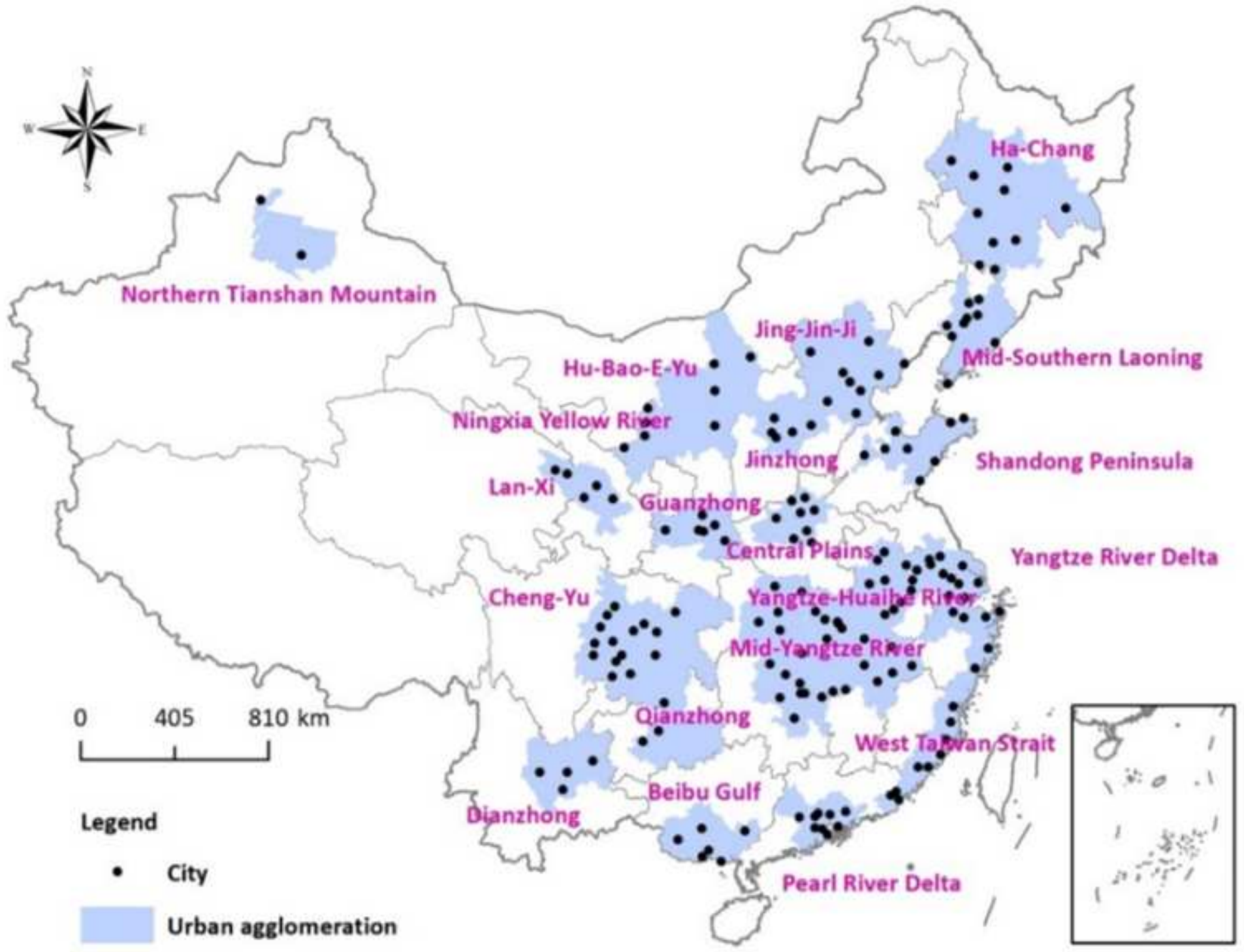

Figure 2

The main urban agglomerations in China. Note: The designations employed and the presentation of the material on this map do not imply the expression of any opinion whatsoever on the part of Research Square concerning the legal status of any country, territory, city or area or of its authorities, or concerning the delimitation of its frontiers or boundaries. This map has been provided by the authors. 


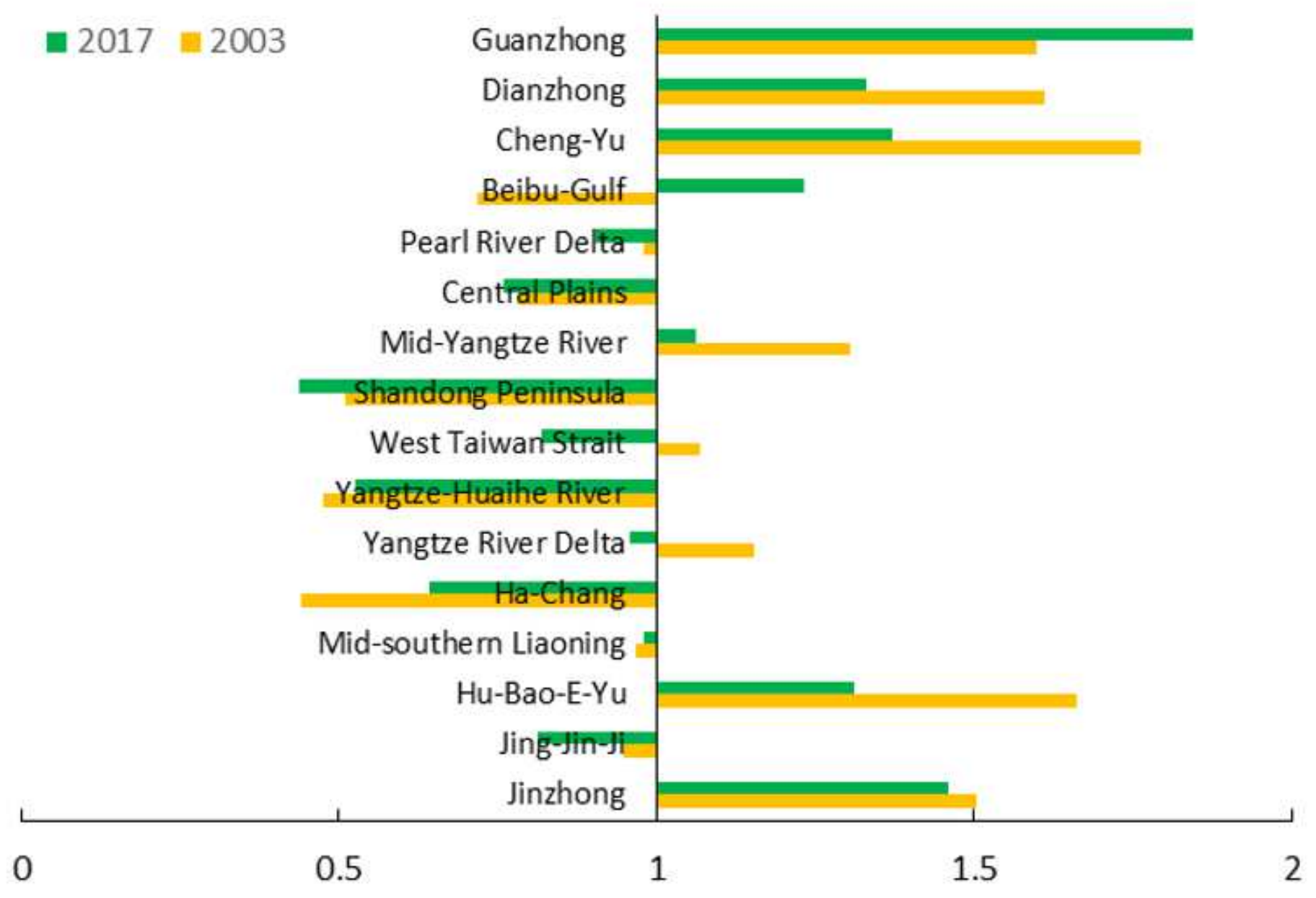

Figure 3

Monocentric index value for 16 urban agglomerations in 2003 and 2017 


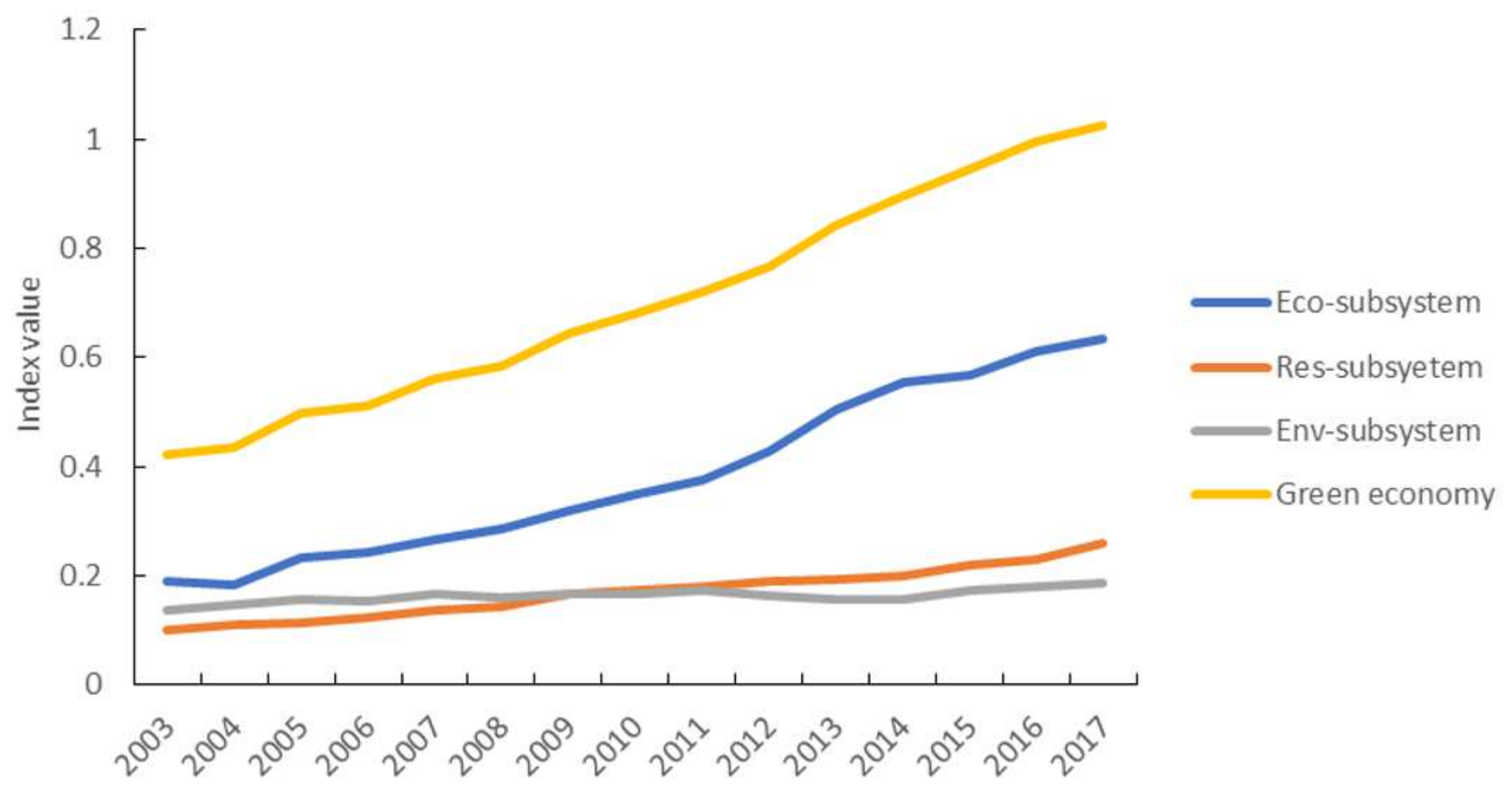

Figure 4

Average scores for green economy and three subsystems across years in 16 urban agglomerations 


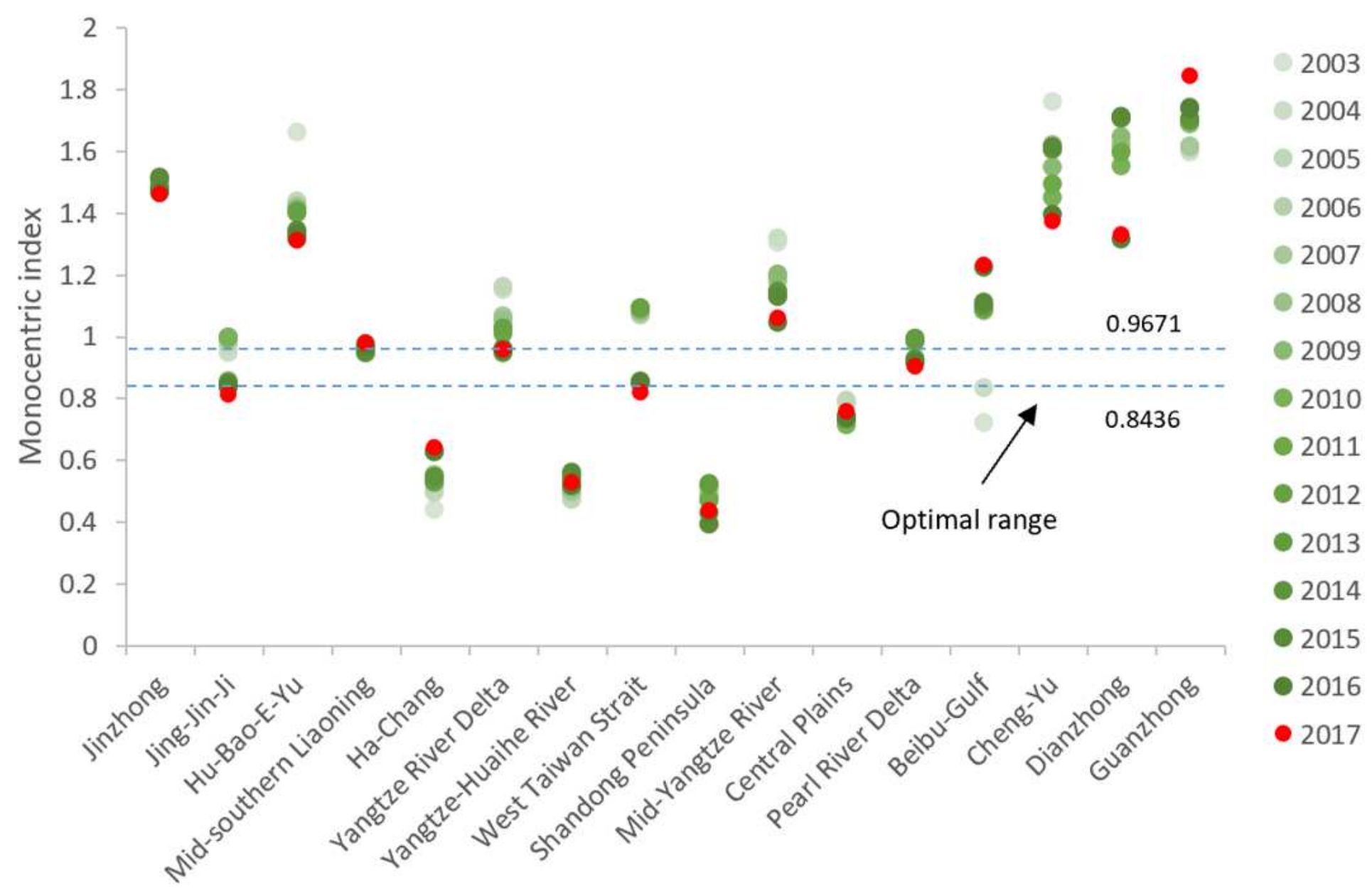

Figure 5

Spatial structure evolution (distribution of monocentric index) for 16 urban agglomerations from 2003 to 2017 and the optimal spatial structure range for green economy 